\title{
Antibacterial potency of different deposition methods of silver and copper containing diamond-like carbon coated polyethylene
}

Norbert Harrasser ${ }^{1,4^{*}}$, Sebastian Jüssen ${ }^{1}$, Andreas Obermeir ${ }^{1}$, Ralf Kmeth², Bernd Stritzker ${ }^{2}$, Hans Gollwitzer ${ }^{1,3}$ and Rainer Burgkart ${ }^{1}$

\begin{abstract}
Background: Antibacterial coatings of medical devices have been introduced as a promising approach to reduce the risk of infection. In this context, diamond-like carbon coated polyethylene (DLC-PE) can be enriched with bactericidal ions and gain antimicrobial potency. So far, influence of different deposition methods and ions on antimicrobial effects of DLC-PE is unclear.

Methods: We quantitatively determined the antimicrobial potency of different PE surfaces treated with direct ion implantation (II) or plasma immersion ion implantation (PIII) and doped with silver (Ag-DLC-PE) or copper (CU-DLC-PE). Bacterial adhesion and planktonic growth of various strains of S. epidermidis were evaluated by quantification of bacterial growth as well as semiquantitatively by determining the grade of biofilm formation by scanning electron microscopy (SEM). Additionally silver release kinetics of Plll-samples were detected.

Results: (1) A significant $(p<0.05)$ antimicrobial effect on PE-surface could be found for Ag- and Cu-DLC-PE compared to untreated PE. (2) The antimicrobial effect of Cu was significantly lower compared to Ag (reduction of bacterial growth by 0.8 (Ag) and $0.3(\mathrm{Cu}$ logarithmic (log)-levels). (3) PIII as a deposition method was more effective in providing antibacterial potency to PE-surfaces than II alone (reduction of bacterial growth by 2.2 (surface) and 1.1 (surrounding medium) log-levels of PIII compared to 1.2 (surface) and 0.6 (medium) log-levels of II). (4) Biofilm formation was more decreased on PIII-surfaces compared to II-surfaces. (5) A silver-concentration-dependent release was observed on PIII-samples.
\end{abstract}

Conclusion: The results obtained in this study suggest that PIII as a deposition method and Ag-DLC-PE as a surface have high bactericidal effects.

Keywords: Implant-associated infections, Diamond-like carbon, Silver, Copper, Staphylococcus epidermidis, Antibacterial coating

\footnotetext{
* Correspondence: Norbert.Harrasser@mri.tum.de

${ }^{1}$ Clinic of Orthopedics and Sports Orthopedics, Klinikum rechts der Isar,

Technical University of Munich, Ismaninger Str. 22, 81675 Munich, Germany

${ }^{4}$ Clinic of Orthopedics and Sports Orthopedics, Klinikum rechts der Isar,

Technical University of Munich, Ismaninger Str. 22, 81675 Munich, Germany

Full list of author information is available at the end of the article
} 


\section{Background}

Implant-associated bacterial infections are one of the most serious complications in orthopedic surgery, representing a significant healthcare and economic burden [1]. Management of these infections often requires multiple debridement surgeries, and long-term systemic antibiotic therapy, despite the associated side effects and additional complications [2]. One of the major problems in septic surgery is the formation of biofilm on implanted foreign materials [3, 4]. These extracellular polysaccharide layers impede the activity of the host defenses and antibiotic therapy, leading to a 1000-fold decreased susceptibility to antimicrobial agents, and further promotion of bacterial survival and growth [5]. Once a significant amount of biofilm has formed, eradication of infection is nearly impossible without removing the implant. Therefore, prevention of these infections has an important impact on patient's morbidity and the cost effectiveness of hospital care [6]. In this context, employment of implant materials or coatings that control infection and biofilm formation are particularly advantageous [7]. This led to the development of antiadhesive and antibacterial surfaces. The first mentioned coatings (e.g. polyethylene glycol, polyethylene oxide brushes) reduce bacterial adhesion by altering the physicochemical properties of the substrate. Thus, formation of protein surface layers (conditioning films) on the implant and bacteria-substrate interactions are hindered [8]. However, the effectiveness of these coatings for reducing bacterial adhesion is very limited and varies markedly depending on bacterial species. On the other hand, nonantibiotic antibacterial coatings actively release bactericidal agents, e.g. silver (Ag)- $[9,10]$ and/or copper $(\mathrm{Cu})$ [11]. In contrast to antibiotics these ions act more broadly against a wide range of bacteria, and microbes that are not intrinsically resistant [12] will rarely develop resistance [13]. However, there are concerns regarding a possible toxicity of silver-coated medical devices [10]. $\mathrm{Cu}$ on the other hand has been shown to possess outstanding antibacterial but nevertheless bio-tolerant features [11, 14]. A problem concerning $\mathrm{Ag}$ and $\mathrm{Cu}$ as bactericidal agents in coatings is the fact that they can hardly be embedded on wear surfaces, e.g. polyethylene (PE). PE is in widespread use in total joint arthroplasty due to its outstanding mechanical properties as a wear surface and simultaneously its high biocompatibility. On the other hand $\mathrm{PE}$ is highly prone to bacterial adherence. In total knee replacement roughly half of the surface is exposed to synovial fluid and in main parts tribologically active. Therefore in septic knee surgery major portions of the susceptible prosthesis are not protected against bacterial reinfection. A potential solution to this problem could be the use of antibacterialagent-enriched diamond-like carbon (DLC) coatings. DLC coatings can act as local antibacterial agents if release of $\mathrm{Ag}\left(\mathrm{Ag}^{+}\right)-$or $\mathrm{Cu}\left(\mathrm{Cu}^{++}\right)$-ions is provided [15-17], and at the same time exhibit excellent tribological features if used for hip or knee arthroplasty [18-21]. In spite of these promising results, to our best knowledge, comprehensive studies on antibacterial effects of DLC coatings on soft wear surfaces, e.g. polyethylene (PE), comparing Ag and $\mathrm{Cu}$ have not been conducted so far. Additionally, data on the use of different deposition methods for DLC coatings and its influence on antimicrobial effects are still lacking.

In this report the antimicrobial effects of $\mathrm{Ag}$ - and $\mathrm{Cu}$ incorporated DLC coatings on PE manufactured with different techniques are described. The coatings and films were deposited by two methods of IBAD (plasma immersion ion implantation (PIII) and conventional ion implantation (II)). Bactericidal potency of DLC specimens enriched with $\mathrm{Ag}$ or $\mathrm{Cu}$ was studied on the surface and the surrounding fluid medium. This study provides valuable information for determining the suitability of DLC-PE enriched with Ag or $\mathrm{Cu}$. Ethics approval for this study was not necessary according to the institutional review board (TU München).

\section{Methods \\ DLC film deposition}

To incorporate $\mathrm{Ag}$ or $\mathrm{Cu}$ homogenously within the DLC matrix of PE-samples modified techniques of ion irradiation of polymers were applied: DLC-processing was achieved by either conventional, direct ion implantation (II) via ion bombardment or plasma immersion ion implantation (PIII) [22]. Both methods are described schematically in Fig. 1. Main disadvantage of conventional II is that only a relatively small part of the surface which is targeted by the beam can be enriched with ions. This makes ion-containing DLC-processing of 3D-surfaces (e.g. joint prostheses) time-consuming and expensive. On the other hand, ion implantation with PIII is easy to perform due to the liquid plasma state of the coating fluid. This allows coating of complex shaped surfaces without major efforts. In contrast to common DLC techniques (e.g., physical vapor deposition) with both methods used in this study the PE-surface is not coated with DLC but rather modified by ion implantation. Due to the kinetic energy of the implanted ions, the polymer surface is modified from crystalline PE to amorphous DLC, while the metal ions agglomerate to nano-particles directly under the surface. In this way, the implantation of ions leads to a wear-resistant, antibacterial PE surface reducing the risk of detachment compared to surface coatings [23].

\section{Sample features}

Study objects were cylindrical substrates (diameter: $10 \mathrm{~mm}$, height: $2 \mathrm{~mm}$; Goodfellow GmbH, Nauheim, Germany) of ultrahigh molecular weight polyethylene $(\mathrm{PE})$. The samples were investigated in different groups 


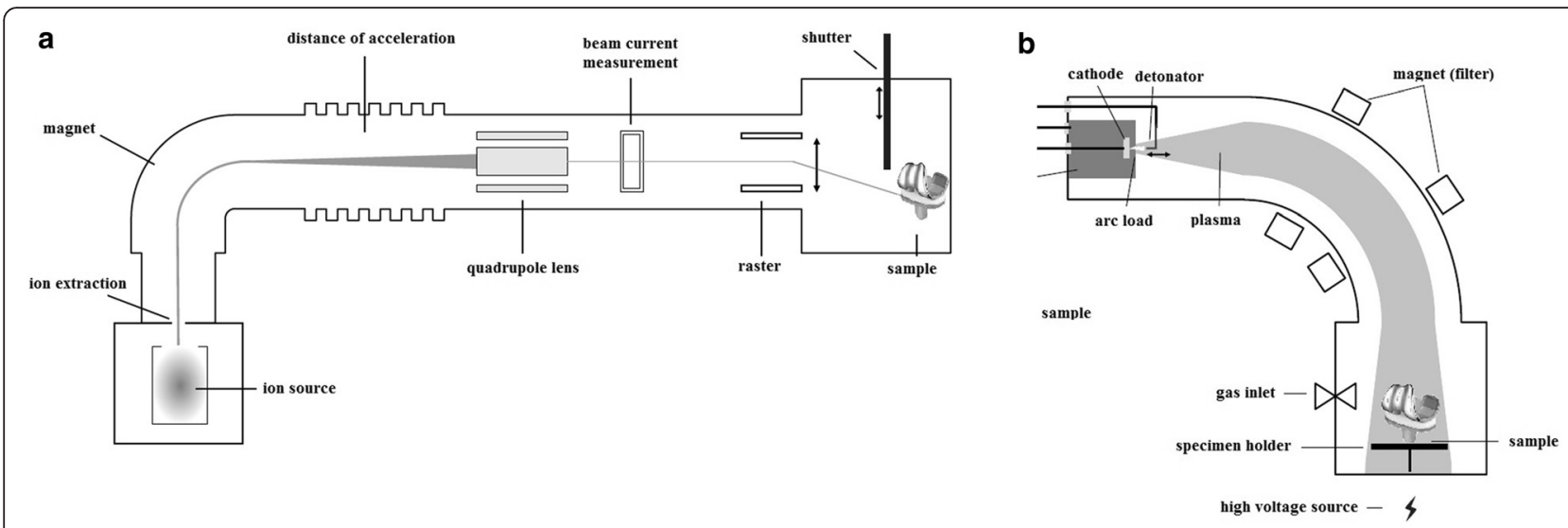

Fig. 1 Scheme of deposition methods for ions: a) direct ion implantation (II), b) plasma immersion ion implantation (PIII); Note: II allows incorporation of ions only on the sample surface struck by the ion beam; PIII allows homogenous incorporation of ions on complex shaped surfaces due to liquid plasma state of the ion beam

with modified parameters of implantation: Firstly, to determine which of the ions ( $\mathrm{Ag}$ or $\mathrm{Cu})$ exhibits higher bactericidal potency (first group) and secondly, to determine the influence of different deposition methods (second group). All sample features and testing groups are given in Table 1.

In the first group Ag-doped (fluence: $1 \times 10^{17} \mathrm{~cm}^{-2}$, ion energy: $60 \mathrm{keV}$ ) and $\mathrm{Cu}$-doped samples (fluence: $1 \times 10^{17} \mathrm{~cm}^{-2}$; ion energy: $55 \mathrm{keV}$ ) were assembled for direct comparison of antibacterial activity of these ions. DLC processing was carried out via II of Ag- or $\mathrm{Cu}$-ions. Ion energy was chosen according to previous results, where these enrgies led to a superficial implantation of ions allowing dissolution onto the surface and therefore exhibiting bactericidal effects. With this features the effect of fluence and implantation depth can be minimized so that the intrinsic bactericidal effects of the ions can be estimated. Ion energy of $\mathrm{Cu}$ -

Table 1 Physical parameters of DLC conversion and antibacterial effect of different surfaces compared to untreated PE

\begin{tabular}{|c|c|c|c|c|c|c|c|c|}
\hline & $\begin{array}{l}\text { DLC-processing } \\
\text { (implantation } \\
\text { energy, fluence) }\end{array}$ & $\begin{array}{l}\text { Surface } \\
\text { adhesion [CFU; } \\
\text { mean }+/- \text { SD] }\end{array}$ & 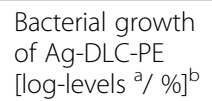 & $p$-values & $\begin{array}{l}\text { Planktonic growth } \\
{[\mathrm{CFU} / \mathrm{ml} ;} \\
\text { mean +/- SD] }\end{array}$ & $\begin{array}{l}\text { Bacterial growth } \\
\text { of Ag-DLC-PE } \\
\left.\text { [log-levels }^{\mathrm{a}} / \%\right]^{\mathrm{b}}\end{array}$ & $p$-values & \\
\hline \multirow{4}{*}{$\begin{array}{l}\text { Comparison of } \\
\text { antibacterial ions } \\
\text { deposited with II: } \\
\text { Ag vs. Cu }\end{array}$} & $\begin{array}{l}\text { II (Ag): } 60 \mathrm{keV}, \\
1 \times 10^{17} \mathrm{~cm}^{-2}\end{array}$ & $2.6 \times 10^{3}+1-2.5 \times 10^{3}$ & $-0.8 /-85.6 \%$ & $<.05^{*}$ & $1.7 \times 10^{5}+/-8.5 \times 10^{4}$ & $+0.05 /+13.3 \%$ & $>.05^{*}$ & 1st Group \\
\hline & $\begin{array}{l}\text { II (Cu): } 55 \mathrm{keV} \\
1 \times 10^{17} \mathrm{~cm}^{-2}\end{array}$ & $9.0 \times 10^{3}+/-2.6 \times 10^{3}$ & $-0.3 /-50.0 \%$ & $<.05^{*}$ & $1,6 \times 10^{5}+/-9.5 \times 10^{4}$ & $+0.03 /+6.6 \%$ & $>.05^{*}$ & 1st Group \\
\hline & \| (Ag) vs. \| (Cu) & & & $<.05$ & & & $>.05$ & 1st Group \\
\hline & Untreated PE & $1.8 \times 10^{4}+/-9.4 \times 10^{3}$ & & & $1.5 \times 10^{5}+/-2.8 \times 10^{4}$ & & & 1st Group \\
\hline \multirow{4}{*}{$\begin{array}{l}\text { Comparison of } \\
\text { deposition } \\
\text { methods: } \\
\text { PIII vs. II }\end{array}$} & $\begin{array}{l}\text { PIII (Ag): } 5 \mathrm{kV} \\
1 \times 10^{17} \mathrm{~cm}^{-2}\end{array}$ & $2,5 \times 10^{2}+/-1.5 \times 10^{2}$ & $-2.2 /-99.1 \%$ & $<.05^{*}$ & $1,1 \times 10^{4}+/-2.5 \times 10^{3}$ & $-1.1 /-96.3 \%$ & $<.05^{*}$ & 2nd Group \\
\hline & $\begin{array}{l}\text { ॥ (Ag): } 10 \mathrm{keV} \\
1 \times 10^{17} \mathrm{~cm}^{-2}\end{array}$ & $2,3 \times 10^{3}+/-3.5 \times 10^{2}$ & $-1.2 /-92.0 \%$ & $<.05^{*}$ & $3,6 \times 10^{4}+/-1.2 \times 10^{3}$ & $-0.6 /-88.0 \%$ & $<.05^{*}$ & 2nd Group \\
\hline & $\begin{array}{l}\text { PIII (Ag) vs. } \\
\|(A g)\end{array}$ & & & $<.05$ & & & $<.05$ & 2nd Group \\
\hline & Untreated PE & $2.9 \times 10^{4}+/-2.0 \times 10^{4}$ & & & $3.0 \times 10^{5}+/-6.5 \times 10^{4}$ & & & 2nd Group \\
\hline
\end{tabular}

\footnotetext{
alog-levels = bacterial counts calculated as shown in following equation: $\log _{\text {-levels }}=\log _{10}\left(\mathrm{CFU}\right.$ of $\mathrm{Ag}$-DLC-PE) - $\log _{10}$ (CFU of untreated PE)
}

${ }^{b}$ positive values (log-levels/\%) express increased bacterial growth on Ag-DLC-PE compared to PE, negative values express reduced bacterial growth on Ag-DLC-PE compared to PE fluence = amount of ions received by a surface per unit area [ions $/ \mathrm{cm}^{2}$ ]

* = compared to untreated PE

PIII (Ag) plasma immersion ion implantation of Ag-ions

II $(\mathrm{Ag} / \mathrm{Cu})$ conventional ion-implantation with $\mathrm{Ag}$ - or $\mathrm{Cu}$-ions

CFU colony forming units

SD standard deviation 
samples was lower compared to Ag-samples due to the fact that $\mathrm{Cu}$-ions penetrate easier into the PE-surface. Therefore $\mathrm{Cu}$-ions reach the same penetration depth as Ag-ions with lower implantation energies. Based on the findings of the first group the second group was assembled with two different methods of ion deposition: PIII (fluence: $1 \times 10^{17} \mathrm{~cm}^{-2}$; pulse voltage: $5 \mathrm{kV}$ ) vs. II (fluence: $1 \times 10^{17} \mathrm{~cm}^{-2}$; ion energy: $10 \mathrm{keV}$ ). Again, different ion energies were applied for either methods to allow equal penetration depth of ions into the samples. Non-modified PE samples served as a control.

After sample preparation incubation for $24 \mathrm{~h}$ with Staphylococcus epidermidis (ATCC35984) was carried out. Thereafter, antimicrobial effects on the sample's surface (i.e. bacterial sessile growth) and the surrounding fluid medium (i.e. bacterial planktonic growth) were investigated.

\section{Evaluation of silver release}

Silver release kinetics was evaluated for samples with the highest intrinsic antimicrobial potency, namely Ag-DLCPE samples deposited with PIII. Sample plates were placed into $10 \mathrm{ml}$ phosphate buffered saline (PBS) and kept sealed for 10 days at $37^{\circ} \mathrm{C}$. Every $24 \mathrm{~h}$ PBS was harvested and replaced. For every Ag-enriched sample type (fluences: $1 \times 10^{17}, 5 \times 10^{16}$ and $1 \times 10^{16} \mathrm{~cm}^{-2}$ ) five specimens were investigated. Untreated PE served as control. Analysis of silver release kinetics of the harvested PBS was conducted via ICP-OES (inductively coupled plasma optical emission spectroscopy, Fa. Varian, Vista-MPX, Kleve, Germany).

\section{Sterilization of samples and sealing of surfaces with paraffin wax}

Samples were treated according to a previously described standardized method [24]. Briefly summarized, specimens were rinsed with distilled water for $10 \mathrm{~min}$, air-dried in a laminar flow cabinet and thereafter sterilized with gammabeam with the dose of $26.5 \mathrm{kGy}$ (Isotron Deutschland $\mathrm{GmbH}$, Allershausen, Germany).

\section{Bacterial sample preparation}

The bacterial strains used in the present study were $S$. epidermidis (ATCC 35984; LGC Standards GmbH, Wesel, Germany) for determination of surface and planktonic growth and a strong biofilm-forming variant of S. epidermidis (RP62a; LGC Standards GmbH, Wesel, Germany) for scanning electron microscopy (SEM-) evaluation of biofilm formation on the samples. These strains are of major clinical importance in implantassociated infections $[25,26]$. Test strains were routinely cultured in Columbia Agar with $5 \%$ sheep blood (S. epidermidis, ATCC 35984) or Trypticase ${ }^{\text {тM }}$ Soy Agar (S. epidermidis, RP62a) (Becton Dickinson, Heidelberg,
Germany) at $37{ }^{\circ} \mathrm{C}$ overnight before testing. Bacteria were then harvested by centrifugation, rinsed, suspended, diluted in sterile phosphate buffered saline (PBS) and adjusted by densitometry to a MacFarland 0.5 standard (MacFarland Densimat ${ }^{\mathrm{TM}}$, BioMérieux, Marcy l'Etoile, France). To control bacterial concentration, $100 \mu \mathrm{l}$ of each suspension was again cultured for $24 \mathrm{~h}$ at $37{ }^{\circ} \mathrm{C}$. After $24 \mathrm{~h}$ serial dilutions of this suspension were plated on Colombia-Agar. The colonies were counted and colony numbers calculated accordingly. For the study every suspension with its known bacterial concentration was diluted with DMEM + 10 \% FCS to reach the targeted value for bacterial concentration $\left(10^{5} \mathrm{CFU} / \mathrm{ml}\right)$. Sample plates with paraffin-coated lower surfaces were placed in 24-well culture plates and $1 \mathrm{ml}$ of $10^{5} \mathrm{CFU} / \mathrm{ml}$ bacterial suspensions were added. Incubation of the well plates was conducted for $24 \mathrm{~h}$ at $37^{\circ} \mathrm{C}$.

\section{Microbiological analysis}

Bacterial surface adhesion was evaluated by determining bacterial concentration on the specimen. Bacterial planktonic growth was measured in the growth medium. For every group four independent testing runs with four different samples were conducted. Therefore, altogether 16 samples were tested for every group.

\section{Determination of bacterial growth on the sample surface}

Colonized sample plates were removed from the wells with a sterile forceps, carefully rinsed twice with sterile PBS, transferred to vials containing $3 \mathrm{ml}$ of sterile PBS and sonicated for $7 \mathrm{~min}$ (Elmasonic S60H, Elma, Singen, Germany) to remove adhering bacteria. $100 \mu \mathrm{l}$ of the fluid were aspirated, plated on Colombia Agar at $37{ }^{\circ} \mathrm{C}$ for $24 \mathrm{~h}$ and quantified after incubation $(\mathrm{CFU} / \mathrm{ml}$, Fig. 2).

SEM-analysis was conducted semiquantitatively to evaluate inhibition of biofilm formation. SEM-images were compiled of native DLC coated PE samples and Ag-DLC-PE samples treated with II and PIII. Biofilm formation was quantified in five categories: (1) no biofilm formation, (2) biofilm covering less than $25 \%$ of the surface, (3) biofilm covering between 25 and $75 \%$ of the surface, (4) biofilm covering more than $75 \%$ of the surface, (5) biofilm formation covering the entire surface. Two different observers (NH, SJ) graded five randomly chosen fields of every sample in three runs.

\section{Determination of bacterial planktonic growth}

A $700-\mu$ l volume of each well was supplemented with $700 \mu \mathrm{l}$ neutralizing solution as described by Tilton: $1,0 \mathrm{~g}$ sodium thioglycolate $+1,46 \mathrm{~g}$ sodium thiosulfate in $1.000 \mathrm{ml}$ deionized water [27]. The neutralizing solution acts as an inhibitor for reminiscent metal toxicity on bacteria. The suspension was plated on Columbia Agar 


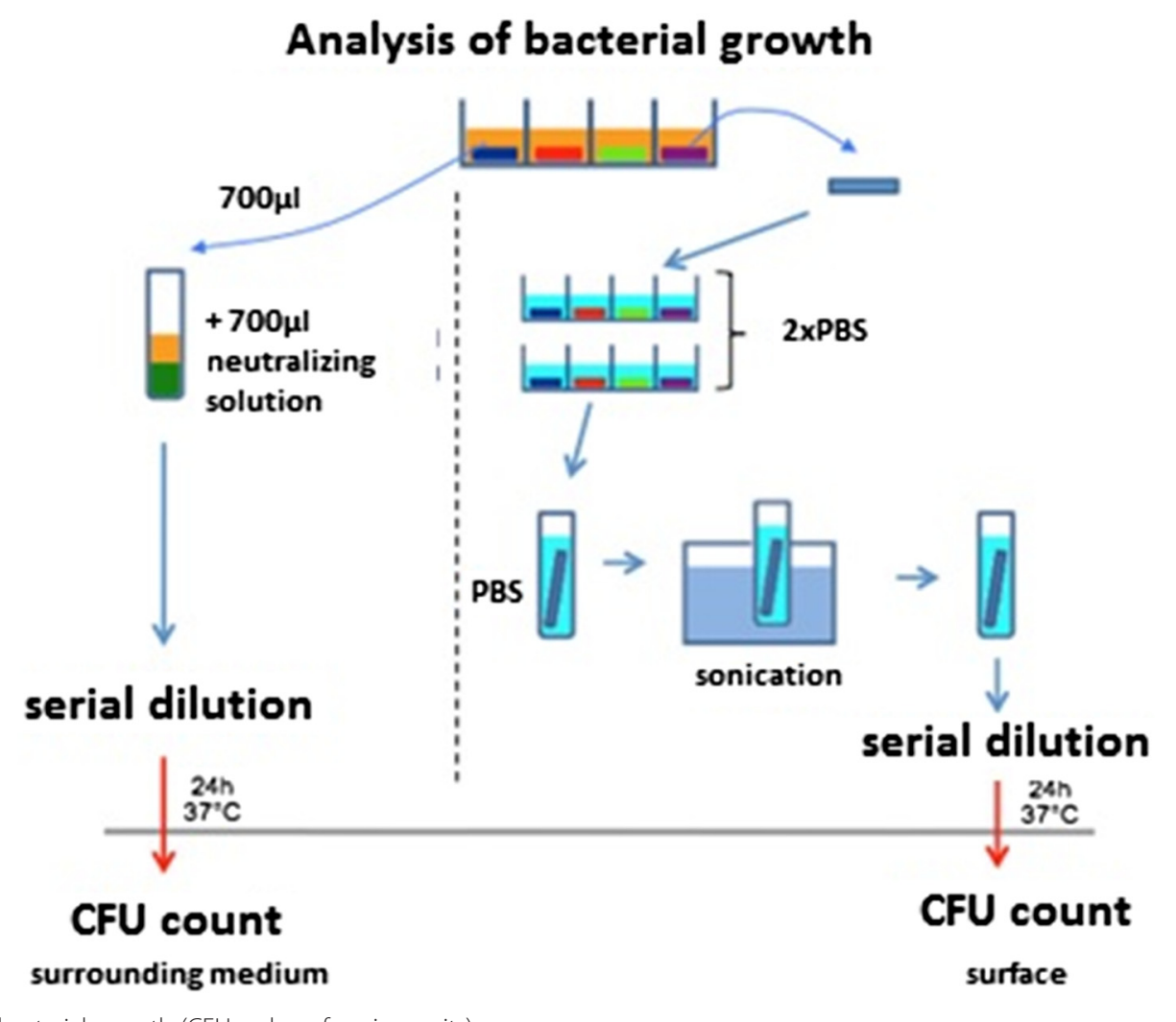

Fig. 2 Analysis of bacterial growth (CFU: colony-forming units)

after serial dilutions and incubated at $37{ }^{\circ} \mathrm{C}$ for $24 \mathrm{~h}$. Thereafter, CFU were quantified and extrapolated to CFU/ml (Fig. 2).

\section{Statistics}

All results are presented as means \pm standard deviation. Statistical significance was computed using nonparametric methods and the method of closed testing procedure (Kruskal-Wallis and Mann-Whitney $U$ test). $P<0.05$ was considered statistically significant. Statistical tests were performed with use of SPSS (version 20.0; Chicago, Illinois). Statistical analysis was conducted per consultation with the Institute of Medical Statistics and Epidemiology (Klinikum rechts der Isar, Technische Universität München, Munich, Germany).

\section{Results}

Antimicrobial effect of $\mathrm{Cu}$ - and Ag-DLC-PE with equal penetration depth of ions in the surface layers (ion energy: $55 \mathrm{keV}$ for $\mathrm{Cu}$ and $60 \mathrm{keV}$ for $\mathrm{Ag}$ ) and equal fluences $\left(1 \times 10^{17} \mathrm{~cm}^{-2}\right)$

Compared to untreated PE on $\mathrm{Cu}$ - and Ag-DLC-PE samples a significantly decreased bacterial growth was evident (Table 1, Fig. 3). Comparison of $\mathrm{Cu}$ - and $\mathrm{Ag}$ DLC-PE samples among each other revealed a significant reduction of bacterial surface growth on Ag-DLC-
PE samples. Analysis of planktonic growth in the supernatant growth medium showed no significant antibacterial effects neither for $\mathrm{Cu}$ - nor Ag-DLC-PE samples (Table 1, Fig. 3). Due to superior bactericidal effects of Ag-DLC-PE compared to Cu-DLC-PE further testing was only conducted with Ag-specimens.

Antimicrobial effect of Ag-DLC-PE processed with different deposition techniques (PIII vs. II) and equal fluences $\left(1 \times 10^{17} \mathrm{~cm}^{-2}\right)$

Samples treated with PIII and II showed both a significantly decreased bacterial surface adhesion compared to PE by 2.2 and 1.2 log-levels respectively. Comparison of PIII and II revealed a significant reduced amount of bacteria for PIII-samples. Analysis of planktonic growth showed again significantly reduced bacterial concentrations for either deposition techniques. Similar differences were found for bacterial concentrations in the surrounding medium (Table 1, Fig. 4).

\section{Surface biofilm formation in scanning electron micrographs}

Biofilm formation was ubiquitous and graded type 5 on all native PE samples. The entire specimen surfaces were covered with thick layers of S. epidermidis. Ag-DLC-PE samples treated with II on the other hand showed 


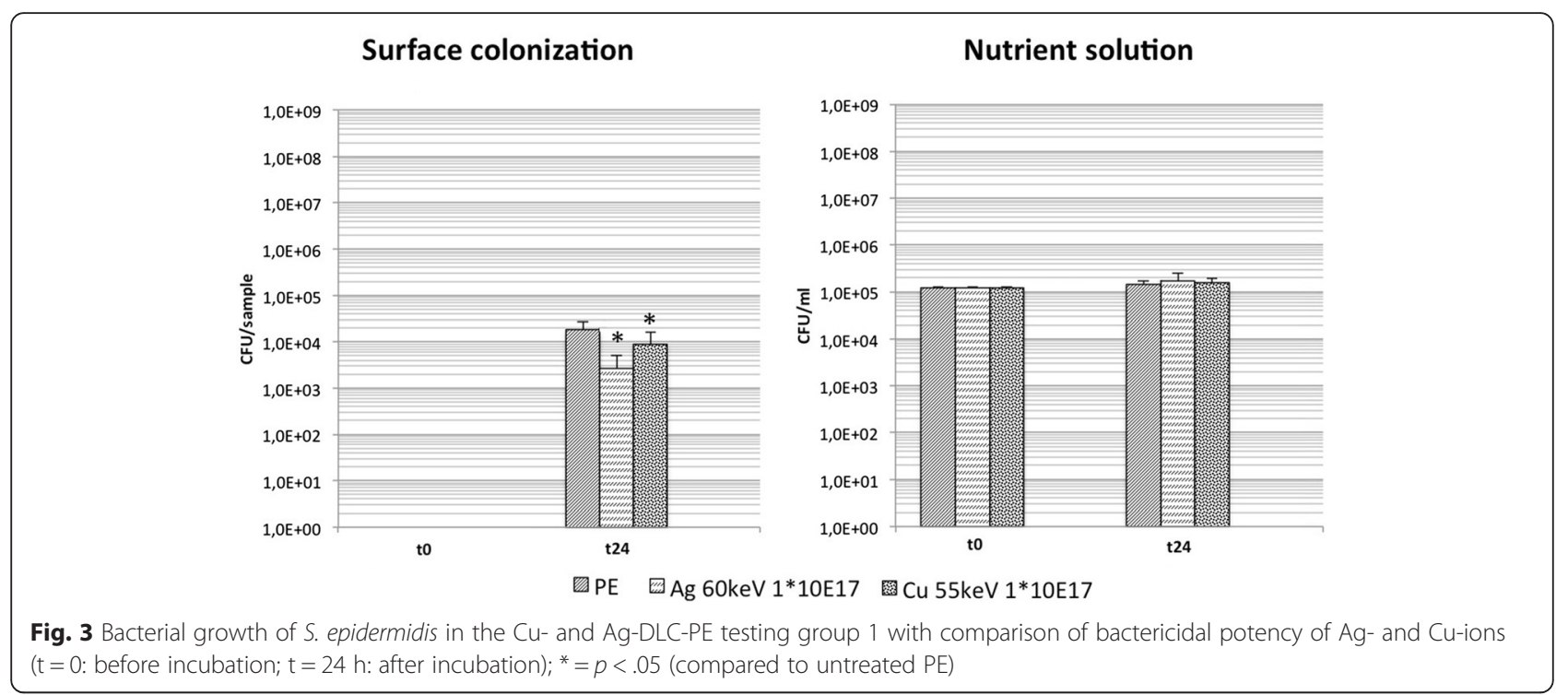

biofilm inhibiting effects with at the most rare spot-like biofilm formation. Average grading for this group were type 4. Samples treated with PIII showed less biofilm formation compared to II-samples. Average grading for this group were type 3 (Fig. 5).

\section{Silver release kinetics}

Silver release kinetics was evaluated for samples which provided the highest bactericidal potency (PIII-samples). Ag concentration of untreated PE throughout the 10 days was considered as the lower detection limit. Due to high sensitivity of the method values were not zero for these specimens. Ag release of specimens with fluences of $1 \times 10^{17} \mathrm{~cm}^{-2}$ and $5 \times 10^{16} \mathrm{~cm}^{-2}$ showed an exponentially decrease up to five days from the beginning of the test (Fig. 6). Thereafter a steady state with minimal decrease of Ag release was achieved. Ag release of Ag-DLC-PE with a fluence of $1 \times 10^{16} \mathrm{~cm}^{-2}$ was equal to the values of untreated $\mathrm{PE}$ and therefore below the lower detection limit.

\section{Discussion}

Since the first applications of surgically-implanted materials in humans, bacterial infections have represented a common and challenging problem $[1,25]$. More than 2.6 million orthopedic implants are performed annually in the United States, hence the incidence of implantassociated infections is also increasing [28]. Most important in the pathogenesis is the colonization of the device surface by formation of a biofilm [9, 29-31], at which Staphylococci and Streptococci are most frequently implicated as the etiologic agents [25, 32].

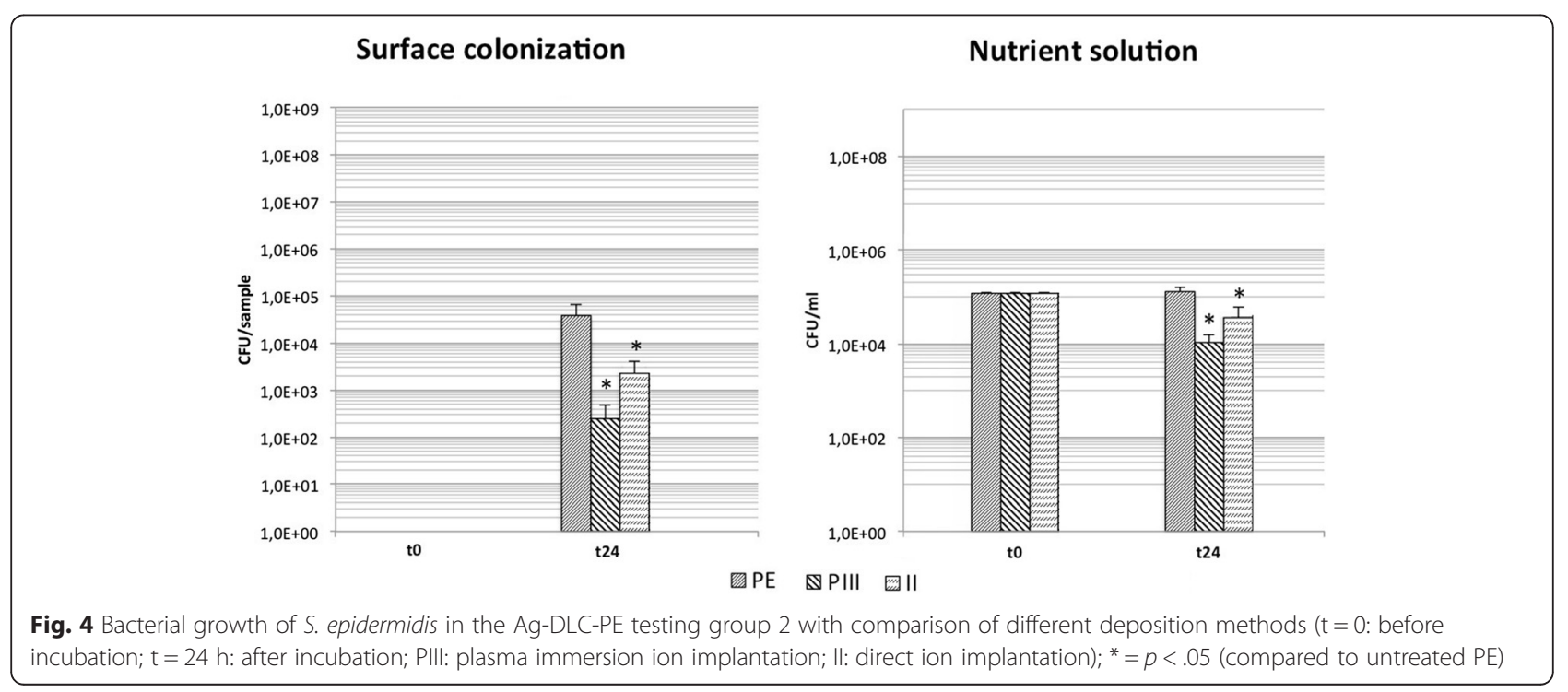



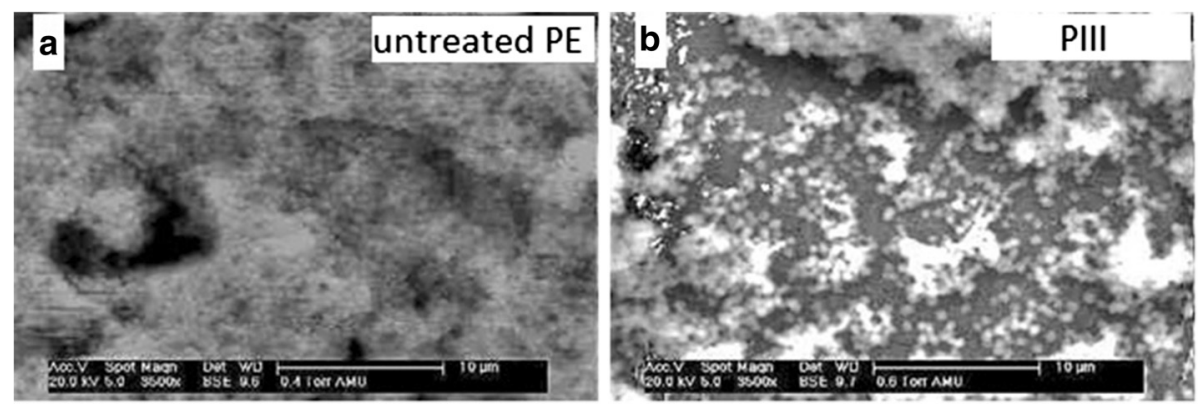

Fig. 5 SEM-images to exemplify biofilm formation on different polyethylene surfaces. Homogenous biofilm grade 5 after incubation with S. epidermidis on native PE (a), reduced biofilm grade 3 on Ag-DLC-PE processed with PIII $\left(5 \mathrm{kV}, 1 \times 10^{17} \mathrm{~cm}^{-2}, \mathbf{b}\right)$

Recent strategies to lower peri-implant infection rates are based on the primary prevention of bacterial adhesion by non-adhesive coatings $[33,34]$ or impairment of bacterial survival and biofilm formation by surface coatings releasing non-antibiotic organic [35-37] and inorganic agents like $\mathrm{Ag}^{+}, \mathrm{Cu}^{++}$or nitric-oxide [12, 38-40]. To our best knowledge, few attempts have been conducted so far to apply $\mathrm{Cu}$ - or Ag-DLC coatings on PE surfaces [24]. DLC surface modifications could be promising, based on the finding that DLC applied at PE is known to exhibit excellent wear behavior [18-20]. A previous study described significant antibacterial potency of Ag-DLC-PE [24], whether DLC coatings enriched with $\mathrm{Cu}$ provide the same ability is still unclear. Additionally, no data are available regarding comparison of different DLC deposition methods.

$\mathrm{Ag}$ seems to be of outstanding value in the prevention and treatment of implant associated infections [41-43]. Ag acts by binding to membranes, enzymes and nucleic acids. Consequently the respiratory chain is inhibited and therefore the aerobe metabolism of microorganisms

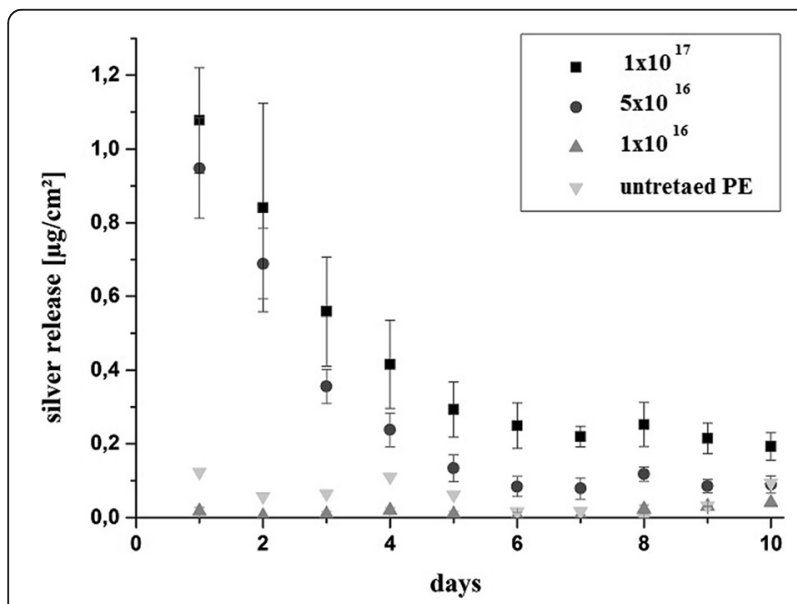

Fig. 6 Silver release kinetics of different Ag-DLC-PE (deposition method: PIII; fluence: $1 \times 10^{17} \mathrm{~cm}^{-2}, 5 \times 10^{16} \mathrm{~cm}^{-2}$, and $1 \times 10^{16} \mathrm{~cm}^{-2}$ ) and untreated PE samples disturbed [9]. Bacteria are quite susceptible to Ag with only negligible possibility of intrinsic resistance [12]. On the other hand, possible toxicity of silver-coated devices is still on debate, which limits its clinical use [10]. Therefore, in the present study one sample series was conducted with $\mathrm{Cu}$-doped DLC coatings since some authors found $\mathrm{Cu}$-ions having an outstanding position as an antibacterial but nevertheless bio-tolerant additive to coatings [14]. Besides these advantages a major disadvantage is the fact that $\mathrm{Cu}$ is difficult to implant on hard surfaces, e.g. titanium. The reason is its low solubility in ethanol-based solutions so that assembly of high dosage colloidal solutions for dip-coating is not possible. $\mathrm{Cu}$ highly tends to agglomerate in polyvinylpyrrolidonematrix [44]. This would be limiting in the manufacturing process of DLC coated joint prostheses.

Our results demonstrated minor antibacterial effects on the surface of $\mathrm{Cu}$ - compared to Ag-DLC-PE samples (Table 1, Fig. 3). This finding was similarly described on other $\mathrm{Cu}$-containing materials by other investigators [39]. We implanted $\mathrm{Cu}$-ions in the same depth of the samples as Ag-ions. This is crucial in the assessment of antibacterial effects. If ion deposition within soft surfaces is performed with high energies $(>80 \mathrm{keV})$ a rather deep deposition and concomitant slow or missing dissolution of ions onto the surface and into the surrounding medium is achieved. Consequently low bactericidal activity of these samples has to be expected [24]. Due to inferior antibacterial effects of $\mathrm{Cu}$ compared to Ag further testing was only conducted with Ag-DLC-PE.

Another finding in the present study was a depositiondepending antibacterial effect of Ag-DLC-PE. A wide variety of techniques have been employed for the synthesis of DLC coatings [19]. Among them, ion beam assisted deposition (IBAD) has great advantages for biomedical applications. It can produce thin films at low substrate temperature suitable for the majority of biomedical materials [45]. The most common used techniques for DLC processing are plasma-based, e.g. chemical vapor deposition (CVD) or physical vapor 
deposition (PVD) [46]. These methods are merely deposition techniques resulting in adhesive problems due to high internal stresses of DLC layers [47]. The methods of DLC processing in the present study (PIII and II) provide penetration of ions into the $\mathrm{PE}$ and concomitant DLC modification of these superficial layers. This fact diminished adhesion problems [48]. In this context, PIII is faster and more cost-effective compared to conventional II and allows DLC coating of complex-shaped surfaces, e.g. joint prostheses [49]. The resulting film properties after PIII treatment should be comparable to those achieved by direct II. On the other hand a clear superiority regarding the bactericidal potency of PIIIsamples compared to II-samples was found in the present study. A possible explanation is a quicker dissolution of Ag-ions from the surface of PIII-samples. Therefore, release kinetics of $\mathrm{Ag}$ was investigated for these specimens. A high and earlier peak of initial dissolution of $\mathrm{Ag}$ for samples with high fluences $\left(\geq 5 \times 10^{16} \mathrm{~cm}^{-2}\right)$ was found (Fig. 6). This "hit-hard-and-early-"effect is certainly crucial for the strong bactericidal potency of these coatings. In this context, a large clinical trial revealed no significant differences between silver-coated and uncoated medical devices [50]. One reason for this finding is that the tested coatings did not actively release silver ions. On the other hand, materials that actively release silver in the surrounding medium however have exhibited strong antibacterial activity [12]. Regarding the results of the present study, it is conceivable that samples with equal fluences but deposited with II would have had a lower peak of Ag release. This results in lower bactericidal potency within the first days due to lack of high concentrations of antibacterial ions on the sample's surface and the surrounding medium. The fact that relatively low concentrated (fluence $<5 \times 10^{16} \mathrm{~cm}^{-2}$ ) Ag-samples deposited with PIII did not release Ag can be explained with the "catching-effect" of low amounts of $\mathrm{Ag}$ in the polymer matrix [1]. In these circumstances no Ag-nanoparticles are formed and therefore $\mathrm{Ag}$ is trapped in superficial PE-layers without the possibility of dissolution.

This study involves several limitations. First, only two bacterial strains were used. Although the investigated strains are of major importance in periprosthetic joint infections, antibacterial effect against other bacteria has to be investigated in future studies. In fact, several studies confirmed even higher bactericidal potency of $\mathrm{Ag}$ against Gram-negative compared to Gram-positive bacteria [51, 52]. Second, $\mathrm{Cu}$ was only used in the first group. It remains unclear, whether $\mathrm{Cu}$ deposited with PIII would lead to increased antibacterial potency in these samples. However, antibacterial effects are caused by the intrinsic activity of the ion and this has been shown to be higher for Ag- compared to $\mathrm{Cu}$-ions. Third, antibacterial effects on the sample surface could be supported by antiadhesive features of DLC alone. A significant antibacterial effect of DLC-PE without integrated $\mathrm{Ag} / \mathrm{Cu}$, on the other hand, could be ruled out in our previous experiments [53]. Fourth, no influence of AgDLC on osseointegration was investigated. A negative effect on eukaryotic cells in this context could be of major interest in the clinical use of this antibacterial coating even though PE is not used with direct bone contact. However, further investigations are needed in order to clear whether the antibacterial effect of Ag-DLC-PE surfaces is sufficient to avoid implant infection in-vivo.

\section{Conclusion}

Taken together, our findings strongly support further investigation of Ag-DLC conversion of PE manufactured with PIII for prophylaxis of implant-associated infections. Antibacterial effectiveness of Ag-DLC-PE has been demonstrated. The suitability of this surface modification for biomedical applications will be confirmed by future studies.

\begin{abstract}
Abbreviations
Ag, Silver; Ag+, silver ion; Ag-DLC, silver incorporated diamond-like carbon coating; Ag-DLC-PE, silver incorporated diamond-like carbon coating on polyethylene; $\mathrm{Cu}$, copper; Cu-DLC-PE, copper incorporated diamond-like carbon coating on polyethylene; DLC, diamond-like carbon; DLC-PE, diamondlike carbon coating on polyethylene; $\mathrm{PE}$, polyethylene; PJl, periprosthetic joint infections
\end{abstract}

\section{Acknowledgements}

We thank PD Dr. Thomas Grupp for providing the PE discs and Jutta Tübel for excellent technical help and advice.

\section{Availability of data and materials}

The dataset supporting the conclusions of this article are included within the article.

\section{Authors' contributions}

$\mathrm{NH}, \mathrm{SJ}$ carried out the microbiological testing and drafted the manuscript. RK and BS provided DLC-processing of samples. HG, RB conceived of the study, and participated in its design and coordination and helped to draft the manuscript. All authors read and approved the final manuscript.

\section{Competing interest}

The authors declare that they have no competing interests.

\section{Financial support}

This work was supported by the "Deutsche Forschungsgemeinschaft (DFG)"within the interdisciplinary project "Quantitative Evaluation der statischen und dynamischen Zelladhäsion und -aktivität an antibakteriellen DLC-Schichten für den biomedizinischen Einsatz" (BU 1154/2-1 and GO 1906/2-1, STR 361/18-1) and partially funded by the Wilhelm-Sander Foundation (Fördernummer: 2009.905.2), which is a charitable, non-profit foundation whose purpose is to promote cancer reasearch.

\section{Author details}

${ }^{1}$ Clinic of Orthopedics and Sports Orthopedics, Klinikum rechts der Isar, Technical University of Munich, Ismaninger Str. 22, 81675 Munich, Germany. ${ }^{2}$ Experimental Physics IV, Institut für Physik, Augsburg University, Universitätsstr. 1, 86135 Augsburg, Germany. ${ }^{3}$ ATOS Clinic, Effnerstr. 38, 81925 Munich, Germany. ${ }^{4}$ Clinic of Orthopedics and Sports Orthopedics, Klinikum rechts der Isar, Technical University of Munich, Ismaninger Str. 22, 81675 Munich, Germany. 


\section{Received: 7 April 2016 Accepted: 27 May 2016} Published online: 06 July 2016

\section{References}

1. Liu Y, Zheng Z, Zara JN, Hsu C, Soofer DE, Lee KS, Siu RK, Miller LS, Zhang X, Carpenter $\mathrm{D}$, et al. The antimicrobial and osteoinductive properties of silver nanoparticle/poly (DL-lactic-co-glycolic acid)-coated stainless steel. Biomaterials. 2012;33:8745-56.

2. Frank RM, Cross MB, Della Valle CJ. Periprosthetic joint infection: modern aspects of prevention, diagnosis, and treatment. J Knee Surg. 2015;28:105-12.

3. Tzeng A, Tzeng TH, Vasdev S, Korth K, Healey T, Parvizi J, Saleh KJ. Treating periprosthetic joint infections as biofilms: key diagnosis and management strategies. Diagn Microbiol Infect Dis. 2015;81:192-200.

4. Matsen Ko LJ, Yoo JY, Maltenfort M, Hughes A, Smith EB, Sharkey PF. The Effect of Implementing a Multimodal Approach on the Rates of Periprosthetic Joint Infection After Total Joint Arthroplasty. J Arthroplasty. 2016:31:451-5.

5. Gbejuade $\mathrm{HO}$, Lovering AM, Webb JC. The role of microbial biofilms in prosthetic joint infections. Acta Orthop. 2015;86:147-58.

6. Baker RP, Furustrand Tafin U, Borens O. Patient-adapted treatment for prosthetic hip joint infection. Hip Int. 2015;25:316-22.

7. Lu H, Liu Y, Guo J, Wu H, Wang J, Wu G. Biomaterials with Antibacterial and Osteoinductive Properties to Repair Infected Bone Defects. Int J Mol Sci. 2016;17.

8. ter Boo GJ, Grijpma DW, Moriarty TF, Richards RG, Eglin D. Antimicrobial delivery systems for local infection prophylaxis in orthopedic- and trauma surgery. Biomaterials. 2015:52:113-25.

9. Gosheger G, Hardes J, Ahrens H, Streitburger A, Buerger H, Erren M, Gunse A, Kemper FH, Winkelmann W, Von Eiff C. Silver-coated megaendoprostheses in a rabbit model-an analysis of the infection rate and toxicological side effects. Biomaterials. 2004;25:5547-56.

10. Hardes J, Ahrens H, Gebert C, Streitbuerger A, Buerger H, Erren M, Gunsel A, Wedemeyer C, Saxler G, Winkelmann W, Gosheger G. Lack of toxicological side-effects in silver-coated megaprostheses in humans. Biomaterials. 2007;28:2869-75

11. Hoene A, Prinz C, Walschus U, Lucke S, Patrzyk M, Wilhelm L, Neumann HG, Schlosser M. In vivo evaluation of copper release and acute local tissue reactions after implantation of copper-coated titanium implants in rats. Biomed Mater. 2013;8:035009.

12. Kumar $\mathrm{R}$, Munstedt $\mathrm{H}$. Silver ion release from antimicrobial polyamide/silver composites. Biomaterials. 2005;26:2081-8.

13. Lee D, Cohen RE, Rubner MF. Antibacterial properties of Ag nanoparticle loaded multilayers and formation of magnetically directed antibacterial microparticles. Langmuir. 2005;21:9651-9.

14. Heidenau F, Mittelmeier W, Detsch R, Haenle M, Stenzel F, Ziegler G, Gollwitzer H. A novel antibacterial titania coating: metal ion toxicity and in vitro surface colonization. J Mater Sci Mater Med. 2005;16:883-8.

15. Cloutier M, Tolouei $R$, Lesage $O$, Levesque L, Turgeon S, Tatoulian M, Mantovani D. On the long term antibacterial features of silver-doped diamondlike carbon coatings deposited via a hybrid plasma process. Biointerphases. 2014;9:029013.

16. Katsikogianni M, Spiliopoulou I, Dowling DP, Missirlis YF. Adhesion of slime producing Staphylococcus epidermidis strains to PVC and diamond-like carbon/silver/fluorinated coatings. J Mater Sci Mater Med. 2006;17:679-89.

17. Dwivedi N, Kumar S, Carey JD, Tripathi RK, Malik HK, Dalai MK. Influence of silver incorporation on the structural and electrical properties of diamondlike carbon thin films. ACS Appl Mater Interfaces. 2013;5:2725-32.

18. Saikko V, Ahlroos T, Calonius O, Keranen J. Wear simulation of total hip prostheses with polyethylene against $\mathrm{CoCr}$, alumina and diamond-like carbon. Biomaterials. 2001;22:1507-14.

19. Dearnaley G. Diamond-like carbon: a potential means of reducing wear in total joint replacements. Clin Mater. 1993;12:237-44.

20. Oliveira LY, Kuromoto NK, Siqueira CJ. Treating orthopedic prosthesis with diamond-like carbon: minimizing debris in Ti6Al4V. J Mater Sci Mater Med. 2014:25:2347-55.

21. Hinuber C, Kleemann C, Friederichs RJ, Haubold L, Scheibe HJ, Schuelke T, Boehlert C, Baumann MJ. Biocompatibility and mechanical properties of diamond-like coatings on cobalt-chromium-molybdenum steel and titanium-aluminum-vanadium biomedical alloys. J Biomed Mater Res A. 2010:95:388-400.

22. Bertóti I, Mohai M, Tóth A, Ujvári T. Nitrogen-PBII modification of ultra-high molecular weight polyethylene: Composition, structure and nanomechanical properties. Surf Coatings Technol. 2007;201:6839-42.

23. Schwarz F, Stritzker B. Plasma immersion ion implantation of polymers and silver-polymer nano composites. Surf Coatings Technol. 2010;204:1875-9.

24. Harrasser N, Jussen S, Banke IJ, Kmeth R, von Eisenhart-Rothe R, Stritzker B, Gollwitzer H, Burgkart R. Antibacterial efficacy of ultrahigh molecular weight polyethylene with silver containing diamond-like surface layers. AMB Express. 2015;5:64

25. Zimmerli W, Ochsner PE. Management of infection associated with prosthetic joints. Infection. 2003;31:99-108.

26. Darouiche RO. Treatment of infections associated with surgical implants. N Engl J Med. 2004;350:1422-9.

27. Tilton RC, Rosenberg B. Reversal of the silver inhibition of microorganisms by agar. Appl Environ Microbiol. 1978;35:1116-20.

28. Kurtz SM, Lau E, Schmier J, Ong KL, Zhao K, Parvizi J. Infection burden for hip and knee arthroplasty in the United States. J Arthroplasty. 2008;23:984-91.

29. Zimmerli W, Moser C. Pathogenesis and treatment concepts of orthopaedic biofilm infections. FEMS Immunol Med Microbiol. 2012;65:158-68.

30. Vilain S, Cosette P, Zimmerlin I, Dupont JP, Junter GA, Jouenne T. Biofilm proteome: homogeneity or versatility? J Proteome Res. 2004:3:132-6.

31. Schwank S, Rajacic Z, Zimmerli W, Blaser J. Impact of bacterial biofilm formation on in vitro and in vivo activities of antibiotics. Antimicrob Agents Chemother. 1998:42:895-8.

32. Hunter G, Dandy D. The natural history of the patient with an infected total hip replacement. J Bone Joint Surg Br. 1977;59:293-7.

33. Groll J, Fiedler J, Bruellhoff K, Moeller M, Brenner RE. Novel surface coatings modulating eukaryotic cell adhesion and preventing implant infection. Int J Artif Organs. 2009;32:655-62.

34. Harris LG, Tosatti S, Wieland M, Textor M, Richards RG. Staphylococcus aureus adhesion to titanium oxide surfaces coated with non-functionalized and peptide-functionalized poly(L-lysine)-grafted-poly(ethylene glycol) copolymers. Biomaterials. 2004;25:4135-48.

35. Bumgardner JD, Wiser R, Elder SH, Jouett R, Yang Y, Ong JL. Contact angle, protein adsorption and osteoblast precursor cell attachment to chitosan coatings bonded to titanium. J Biomater Sci Polym Ed. 2003:14:1401-9.

36. Verraedt E, Braem A, Chaudhari A, Thevissen K, Adams E, Van Mellaert L, Cammue BP, Duyck J, Anne J, Vleugels J, Martens JA. Controlled release of chlorhexidine antiseptic from microporous amorphous silica applied in open porosity of an implant surface. Int J Pharm. 2011;419:28-32.

37. Baffone W, Sorgente G, Campana R, Patrone V, Sisti D, Falcioni T. Comparative effect of chlorhexidine and some mouthrinses on bacterial biofilm formation on titanium surface. Curr Microbiol. 2011:62:445-51.

38. Zhao L, Wang H, Huo K, Cui L, Zhang W, Ni H, Zhang Y, Wu Z, Chu PK. Antibacterial nano-structured titania coating incorporated with silver nanoparticles. Biomaterials. 2011;32:5706-16.

39. Fiedler J, Kolitsch A, Kleffner B, Henke D, Stenger S, Brenner RE. Copper and silver ion implantation of aluminium oxide-blasted titanium surfaces: proliferative response of osteoblasts and antibacterial effects. Int J Artif Organs. 2011;34:882-8

40. Holt J, Hertzberg B, Weinhold P, Storm W, Schoenfisch M, Dahners L. Decreasing bacterial colonization of external fixation pins through nitric oxide release coatings. J Orthop Trauma. 2011:25:432-7.

41. Morones JR, Elechiguerra JL, Camacho A, Holt K, Kouri JB, Ramirez JT, Yacaman MJ. The bactericidal effect of silver nanoparticles. Nanotechnology. 2005:16:2346-53.

42. Taglietti A, Diaz Fernandez YA, Amato E, Cucca L, Dacarro G, Grisoli P, Necchi V, Pallavicini P, Pasotti L, Patrini M. Antibacterial activity of glutathione-coated silver nanoparticles against Gram positive and Gram negative bacteria. Langmuir. 2012;28:8140-8

43. Hardes J, von Eiff C, Streitbuerger A, Balke M, Budny T, Henrichs MP, Hauschild G, Ahrens H. Reduction of periprosthetic infection with silvercoated megaprostheses in patients with bone sarcoma. J Surg Oncol. 2010:101:389-95.

44. Schwarz F, Thorwarth G, Stritzker B. Synthesis of silver and copper nanoparticle containing a-C:Hby ion irradiation of polymers. Solid State Sci. 2009;11:1819-23. 
45. Du C, Su XW, Cui FZ, Zhu XD. Morphological behaviour of osteoblasts on diamond-like carbon coating and amorphous C-N film in organ culture. Biomaterials. 1998;19:651-8.

46. Love CA, Cook RB, Harvey TJ, Dearnley PA, Wood RJK. Diamond like carbon coatings for potential application in biological implants, Äîa review. Tribology Int. 2013:63:141-50.

47. Walter KC, Nastasi M, Munson C. Adherent diamond-like carbon coatings on metals via plasma source ion implantation. Surf Coat Technol. 1997:93:287-91

48. Liu XY, Chu PK, Ding CX. Surface modification of titanium, titanium alloys, and related materials for biomedical applications. Mater Sci Eng R-Rep. 2004;47:49-121.

49. Mändl S, Krause D, Thorwarth G, Sader R, Zeilhofer F, Horch HH Rauschenbach B. Plasma immersion ion implantation treatment of medical implants. Surf Coatings Technol. 2001;142-144:1046-50.

50. Riley DK, Classen DC, Stevens LE, Burke JP. A large randomized clinical trial of a silver-impregnated urinary catheter: lack of efficacy and staphylococcal superinfection. Am J Med. 1995;98:349-56.

51. Flores CY, Minan AG, Grillo CA, Salvarezza RC, Vericat C, Schilardi PL. Citratecapped silver nanoparticles showing good bactericidal effect against both planktonic and sessile bacteria and a low cytotoxicity to osteoblastic cells. ACS Appl Mater Interfaces. 2013:5:3149-59.

52. Kim JS, Kuk E, Yu KN, Kim JH, Park SJ, Lee HJ, Kim SH, Park YK, Park YH, Hwang CY, et al. Antimicrobial effects of silver nanoparticles. Nanomedicine. 2007;3:95-101.

53. Harrasser N, Jussen S, Banke IJ, Kmeth R, von Eisenhart-Rothe R, Stritzker B, Gollwitzer H, Burgkart R. Antibacterial efficacy of titanium-containing alloy with silver-nanoparticles enriched diamond-like carbon coatings. AMB Express. 2015;5:77.

\section{Submit your next manuscript to BioMed Central and we will help you at every step:}

- We accept pre-submission inquiries

- Our selector tool helps you to find the most relevant journal

- We provide round the clock customer support

- Convenient online submission

- Thorough peer review

- Inclusion in PubMed and all major indexing services

- Maximum visibility for your research

Submit your manuscript at www.biomedcentral.com/submit 